Руднев В.П.

Деперсонализация и реперсонализация (На материале пьесы Бернарда Шоу «Дом, где разбиваются сердца» и фильма Александра Сокурова «Скорбное бесчувствие»)

\begin{abstract}
Аннотация: Статья посвящена анализу пьесы Бернарда Шоу «Дом, где разбиваются сердца» и поставленному по мотивам этой пьесы фильму Александра Сокурова «Скорбное бесчувствие». В основе анализа лежит разграничение понятий деперсонализации и реперсонализации. Этот концепт, предложенный автором статьи, означает оживление личности, становление человека самим собой, индивидуацию, метанойю. Все персонажи пьесы Шоу и фильма Сокурова, деперсонализированные окружающей их обстановкой войны, реперсонализируются в финале с приближением неизбежной смерти. В статье также в рамках разрабатываемого автором метода психосемиотики рассматриваются ассоциативные идентификации персонажей пьесы и фильма. Так капитан Шотовер предстаёт Сталиным, Брежневым, пророком Моисеем, Христом, Богом Отцом, капитаном Ахавом. Элли Дэн - это и «Алиса в стране чудес», и Элли из «Волшебника изумрудного города». Фильм Сокурова (1986) рассматривается как посвященный деперсонализированной советской интеллигенции перед наступлением перестройки. $B$ статье используется метод, разрабатываемый автором на протяжении многих лет на стыке психоанализа, поэтики и семиотики. Он назван психосемиотикой. Новизна данного исследования заключается прежде всего в том, что автор на материале пьесы Бернарда Шоу «Дом, где разбиваются сердиа» и фильма Александра Сокурова «Скорбное бесчувствие» наряду с общепринятым термином деперсонализация вводит свой концепт реперсонализация, означающий становление человека самим собой, индивидуацию, метанойю. Также в статье на основе психосемиотического метода исследуются ассоциативные идентификации персонажей пьесы и фильма.
\end{abstract}

Ключевъе слова: Бернард Шоу, Александр Сокуров, Скорбное бесчувствие, деперсонализация, реперсонализация, смерть, постмодернизм, перестройка, животное, дом.

Review: The present article is devoted to the analysis of Bernard Shaw's play 'Heartbreak House' and Alexander Sokurov's film 'Mournful Unconcern' that was made after the play. The analysis is based on the differentiation between the terms 'depersonalisation' and 'repersonalisation'. This concept offered by the author of the article means the revitalization of personality, his going back to being himself, individuation and metanoia. All characters of Shaw's play and Sokurov's film are depersonalised by the war situation and repersonalised at the end when the inevitable death approaches. Appying his own method of psychosemiotics, the author of the article also analyzes associative identifications of the characters of both play and film. For example, Captain Shotover is associated with Stalin, Brezhnev, Moses, Christ, God the Father and Captain Ahab. Ellie Dunn is both Alice in Wonderland and Ellie from The Wizard of the Emerald City. Sokurov's film (1986) is viewed as a film devoted to the depersonalised Soviet intelligentsia before perestroika. In his research Rudnev has used the method that he has been developing for many years. This method involves psychoanalysis, poetics and semiotics and called 'psychosemiotics'. The novelty of the present research is first of all caused by the fact that based on the study of Bernard Shaw's play 'Heartbreak House' and Alexander Sokurov's film 'Mournful Unconcern' Rudnev introduces the concept of repersonalisation along with a generally accepted term 'depersonalisation'. The researcher defines repersonalisation as individuation and metanoia and one's going back to being himself. Using the psychosemiotic method, the author has also studied associative identifications of the play and film characters.

Keywords: Postmodernisn, death, repersonalisation, depersonalisation, Mournful Unconcern, Alexandr Sokurov, Bernard Show, reconstruction, animal, home. 
Д еперсонализация (старое латинское название anastesia psyhica dolorosa - подзаголовок фильма Сокурова) может быть двух типов.

Психастеническая деперсонализация невротический механизм защиты, при котором человек ощущает чувство собственной измененности по отношению к себе прежнему и окружающему миру (подробно такого рода деперсонализацию исследовал А. А. Меграбян [2]).

Шизофреническая деперсонализация (=дереализация) - психотический или субпсихотический механизм защиты, при котором человек чувствует, что он это не он, а кто-то другой. Шизофреническая деперсонализация сродни бреду воздействия (синдрому Кандинского-Клерамбо), когда у человека «в голове» появляется «кто-то другой», который начинает руководить его действиями.

В принципе мы исходим из такой точки зрения, в соответствии с которой любое состояние сознания является деперсонализированным:

«Итак, при деперсонализации человек может жить как во сне. И любое состояние сознания может рассматриваться как измененное. Что значит, жить, как во сне? Это значит, по-видимому, что все окружающее кажется нереальным, иллюзорным, или что он это не он, а неизвестно кто. Но во сне человеку часто кажется, что он это он и что вокруг все реально. Может быть, наоборот можно сказать, что лишь во сне человек становится самим собой, что именно во сне его состояние может быть неизмененным. Я готов обдумать эту мысль. Тогда надо сначала понять, что значит, какой человек на самом деле. Может быть, такой, каким он хочет, чтобы его видели, или каким он хочет, чтобы его сам себя видел или, может быть, это его внутренняя сущность по Гурджиеву, то есть то состояние, в котором человек пребывает в младенчестве, пока у него не сформировалась личность (=ложная личность) под влиянием воспитания, то есть культуры в широком смысле. Состояние сна тогда и есть возврат к естественности, к младенчеству, когда он только и делает, что спит. С этой точки зрения как будто можно сказать, что состоя- ние сна это поистине сущностное состояние сознания человека. Но ведь человеку во сне снится порой то, что он видел или переживал наяву, или то, что он бы хотел или не хотел видеть наяву, он проигрывает во сне какие-то культурные паттерны и так далее. Обсудим идею, в соответствии с которой любое состояние сознания является измененнъљм. Ну, например, человек идет по улице, просто идет, настроение у него ни плохое, ни хорошее, он идет ни медленно, ни быстро. Он просто идет. Куда он идет? Он идет в магазин, чтобы купить картошки. Кто этот человек? Да кто угодно. Он может быть слесарем, а может быть доктором филологических наук. У него нет никакого счастья и никакого горя. Можно ли сказать, что у этого человека неизмененное состояние сознания? Я так не считаю. Если человек идет за картошкой, то значит, ему нужна еда. Если он идет за картошкой, значит, он беден, потому что богатый человек не станет сам покупать себе картошку, кроме того, это еда для бедных. Хорошо, допустим, что картошка ему напоминает детство - в этом нет ничего измененного. Он просто вспомнил, как его мама в детстве кормила картошкой. И у него было счастливое детство. И у него не было тяжелого Эдипова комплекса. И его отец не был алкоголиком и не избивал мать и т. д. Все у него было более или менее хорошо. Он просто идет по улице в магазин. Но если он идет в магазин, значит, ему это зачем-то нужно. Он просто хочет купить картошки и пожарить ее, чтобы вспомнить детство. А зачем ему вспоминать детство? Почему он хочет вспомнить, что мама кормила его именно картошкой, а не селедкой? Потому что, скажем, он помнит, как ему в детстве отец рассказывал, что революционеров кормили в тюрьме селедкой, а потом не давали пить. А с картошкой у него связана песня «Здравствуй, милая картошка!» Но тогда получается, что с картошкой у него связаны приятные воспоминания, то, что я в книге «Новая модель времени» назвал плюс-первосценой. Но состояние хорошего воспоминания это измененное состояние» [5].

Такое расширенное понимание деперсонализации исходит из того, что между психической нормой и психической патологией 
нет четких границ. Мы рождаемся и умираем каждую минуту. Что мы этим хотели сказать. Мы можем это объяснить про помощи теории трех гун средневековой индийской философии санкхья, изложенной, в частности, в «Бхагават гите», в соответствии с которой «гуны вращаются в гунах». Статическое «депрессивное» начало (тамас) сменяется динамическим «гипоманиакальным началом» (раджас), а оно в свою очередь гармоническим уравновешивающим началом (саттва). В этом смысле каждое мгновение жизни человек находится в определенном состоянии, измененном, по отношению к предыдущему и последующему. И с этой точки зрения можно сказать, что человек всегда так или иначе деперсонализирован чаще в первом и реже во втором смысле.

Противоположное деперсонализации состояние мы называем реперсонализациeй, при которой человек становится самим собой, оживает от защитно-приспособительного онемения. Что значит, что человек становится самим собой? Это значит, что он оживает, начинает «помнить себя». Самовоспоминание - термин Г. И. Гурджиева. Это мистическое состояние, которого удается добиться при помощи долгих ментальных и физических упражнений, результатом которых может стать переход человека на новую ступень сознательности. Ученик Гурджиева Морис Николл называет это метанойя, то есть «изменение ума». Это греческое евангельское слово, которое, по мнению Николла неправильно переведено как покаяние [3]. Примерно такое состояние мы называем реперсонализацией.

Бернард Шоу начал писать «Дом, где разбиваются сердца» в 1913 году, перед началом первой мировой войны, и закончил в 1919м. В этом смысле можно сказать, что деперсонализация была социально-психологическим механизмом на страшное событие мировой войны. В «Доме» Шоу показывает, как деперсонализируются персонажи, занятые своими личными делами, чтобы отгородиться от ужасов международной бойни. Но в результате они приходят к осознанию самих себя (реперсонализции) в финале пьесы хотя бы и под влиянием влечения к смерти, ожидания ее.

Капитан Шотовер. Тридцать фунтов первоклассного динамита - и попусту! Мадзини. Ах, бедный Менген!
Гектор. Да что вы, бессмертный, что ли, что жалеете его? Теперь наша очередь.

Все молча, в страшном напряжении, ждут. Гесиона и Элли крепко держат друг друга за руки. Доносится отдаленнъцй взрыв.

Миссис Хэшебай (выпуская руку Элли). Ах, они пролетели мимо!

Леди Эттеруорд. Опасность миновала. Рэнделл, идите спать.

Капитан Шотовер. Все по местам. Корабль невредим.

(Садится и тут же засыпает.)

Элли (в отчаянии). Невредим!

Гектор (с омерзением). Да. Невредим. И до чего же опять стало невыносимо скучно. (Садится).

Мадзини (садясь). Как я, оказывается, ошибся, - ведь вот мы все уцелели, а Менген и бродяга...

Гектор. Два вора...

Леди Эттеруорд... два деловых человека. Мадзини...оба погибли. А бедному священнику придется, по-видимому, строить себе новый дом.

Миссис Хэшебай. Но какое замечательное ощущение! Я думаю - может быть, они завтра опять прилетят.

Элли (сияя в предвкушении этого). Ах, я тоже думаю!

Александр Сокуров создал свой фильм «Скорбное бесчувствие» (еще одно название деперсонализации) в 1986 г. (вышел на экраны в 1987-м). Это было самое начало перестройки, на которое у многих российских интеллигентов была реакция деперсонализации: «Пусть они (власть) делают, что хотят, мы в это не верим, видели, чем это закончилось после хрущевской оттепели, поэтому не будем обращать внимания на них и продолжать заниматься своими делами». Лишь когда в 1989 году советские журналы начали публиковать «Архипелаг ГУЛаг» А. И. Солженицына, интеллигенты поверили в перестройку и начали реперсонализироваться. Они поверили Ельцину и Гайдару, поверили в нравственную свободу, которую они связывали с этими людьми.

Слово «скорбный» в названии фильма Сoкурова отсылает к названию знаменитой статьи Фрейда «Скорбь и меланхолия», написанной в 1917 г., во время войны. Если первой реакцией на войну была деперсонализация, то второй реакцией была депрессия. 
Если верно, что главное в этиологии депрессии - это «утрата любимого объекта», то в результате первой мировой войны был утрачен чрезвычайно важный объект - уютная довоенная Европа, в которой самым страшным событием в жизни была не газовая атака и не оторванные ноги, а ситуация, когда слишком пылкий обожатель невзначай прикоснется к даме своим жезлом (отчего она потом долго и тяжко болеет!).

Но помимо утраты идеологической, которая породила целую волну культурных деятелей, отразивших это положение вещей с утраченным довоенным житьем - их называли «потерянным поколением», - утраты были и в прямом смысле: на первой мировой войне погибли миллионы людей - жены остались без мужей, дети без отцов и матери без сыновей [4].

Результатом этой социальной послевоенной депрессии стала литература потерянного поколения - «Смерть героя» Ричарда Олдингтона, «Черный обелиск» Ремарка, «Великий Гетсби» Фицджеральда» «Прощай, оружие!» Хемингуэя и многие другие. В своем фильме Сокуров совмещает время первой мировой войны и - по заветам своего учителя Андрея Тарковского («Зеркало») - брежневское время и несомненно рассказывает о брежневском «потерянном поколении», когда интеллигенты ушли в себя, в свои внутренние отношения, а власть их совершенно не интересовала. Что же их интересовало? В центре пьесы Шоу и фильма Сокурова - старик капитан Шотовер, который среди множества других идентификаций воплощает образ Сталина. Его играет грузинский актер Рамаз Чхиквадзе. Он курит трубку, делает вид, что не узнает приехавшую после долгих лет разлуки дочь Ариадну и не хочет принимать участие в ее судьбе (ср. реакцию Сталина на плен его сына и предложение немцев обменять его на фельдмаршала Паулюса: «Я рядовых на фельдмаршалов не меняю»). Шотовер так же обаятелен и коварен, каким был Сталин в глазах современников. Он так же подозрителен (ср. диагноз «паранойя», который поставил Сталину Бехтерев). Но главное, он воплощает абсолютную власть в доме. Он препятствует тому, чтобы Элли вышла замуж за мерзавца Менгена и сам «соблазняет» ее на «мистический брак». Он командует над всеми в доме, и домочадцы говорят о нем, что он сумасшедший. В то же время. Шотовер это и Брежнев: он вечно пьян и добродушен. Шотовер общается со стариком Бернардом Шоу, который живет тут же в доме, читает свою книгу и, заглядывая в лицо Шотовера, как бы спрашивает его, почему все идет не так, как в его пьесе. В результате Шотовер просто выбрасывает старика Шоу в окошко, что знаменует «смерть автора», постмодернистскую парадигму, отказ от авторитарности автора. Теперь персонажи сами делают, что хотят. К чему же это приводит? Шотовер, вообразив себя Христом, призывает всех к покаянию (первый этап реперсонализации). Все весело каются, потому что пока это не подлинная метанойя.

Элли Дэн, которая приехала в дом как невеста псевдомагната Менгена. Она ассоциируется с Алисой, попавшей в страну чудес и ставшей в конце-концов взрослой, но поплатившейся за это сильной деперсонализацией. Разочарованная в своем возлюбленном Марке, который оказался мужем Гесионы, старшей дочери Шотовера, Гектором, она говорит, что ей теперь «все равно» (типичный деперсонализационный аффект).

С другой стороны, «деточка Элли» это, конечно, Элли из сказки Л. Ф. Баума «Великий волшебник из страны Оз» (1900), известной более у нас как «Волшебник изумрудного города» Александра Волкова. Этим волшебником, конечно, является капитан Шотовер, который не позволяет Элли вернуться в родной Канзас. Фильм кончается тем, что в дом попадает бомба, и все кроме погибших Менгена и Рендела, мужа Ариадны, спасаются на Ноевом ковчеге.

Приведем примеры деперсонализации и реперсонализации в пьесе Шоу «Дом, где разбиваются сердца».

Элли. Не понимаю, как это может быть. Вы, верно, хотите заставить меня почувствовать, что я вам ничем не обязана, чтобы я могла решить совершенно свободно, - так?

Менген (встает, с вызывающим видом). Нет. Я хочу сказать именно то, что я говорю.

Элли. Но какая же вам была польза разорять моего отца? Ведь деньги, которые он потерял, это же были ваши деньги?

Менген (с язвительным смехом). Да. Мои. Они и есть мои, мисс Элли. И все деньги, которые вместе с ним потеряли его друзья, тоже мои деньги. (Засовъ- 
вает руки в карманы и ухмыляется.) Я просто их выкурил, как выкуривают пчел из улья. Что вы на это скажете? Вас это несколько потрясает, не так ли?

Әлли. Сегодня утром это могло бы меня потрясти. А сейчас вы даже и представить себе не можете, как мало это для меня значит.

Элли (опуская рукu). Как странно, что моя мать, которая ничего не понимала в делах, была совершенно права относительно вас! Она всегда говорила - конечно, не в присутствии папы, а нам, детям, - что вы вот именно такой человек! Менген (выпрямляется, сильно задеmый). Ах, она так говорила? И тем не менее она не возражала против того, чтобы вы вышли за меня.

Әлли. Видите ли, мистер Менген, моя мать вышла замуж за очень хорошего человека - потому что, как бы вы там ни оценивали моего отца с деловой точки зрения, он - сама доброта, - и ей совсем не хотелось, чтобы я повторила ее опыт.

Менген. Во всяком случае, вы-то теперь уж не пойдете за меня замуж, не правда ли?

Элли (совершенно спокойно). Да нет, почему же?

Менген (встает ошеломленный). Почему?

Әлли. Я не вижу оснований, почему бы мы не могли с вами поладить.

Менген. Да, но, послушайте, вы понимаете... (Он умолкает, совершенно сбитый с толку.)

Әлли (терпеливо). Да?

Менген. Я думал, что вы более щепетильны в ваших взаимоотношениях с людьми. Элли. Если бы мы, женщины, были слишком щепетильны по отношению к мужчинам, нам тогда вовсе не пришлось бы выходить замуж, мистер Менген.

Менген. Такой ребенок, как вы, и слышать от вас: «Мы, женщины»! Куда же дальше! Нет, не может быть, чтобы вы это говорили серьезно.

Элли. Совершенно серьезно. А разве вы. - нет?

Менген. Вы хотите сказать, что вы не собираетесь от меня отказываться.

Элли. А вы хотите отказаться?

Элли. Ступайте, мистер Менген. Вам будет полезно. Гесиона вас утешит.
Миссис Хэшебай (взяв его под руку, поднимает его). Идемте, Альфред. Луна. Ночь. Прямо как в «Тристане и Изольде». (Гладит его руку и тащит его $к$ двери в сад.)

Менген (упирается, но поддается). И как это у вас духу хватает, сердца... (Чувства его прорываются наружу, из-за двери доносятся его рыдания.)

Леди Эттеруорд. Что за непонятная манера вести себя? Что с ним такое, с этим человеком?

Элли (странно спокойным голосом, устремив глаза в какую-то воображаемую даль). У него разбивается сердце, вот и все.

В дверях кладовой появляется капитан и слушает.

Странное это ощущение - боль, которая милосердно уводит нас за пределы наших чувств. Когда сердце разбито, все корабли сожжены, тогда уж все, все равно. Конец счастья и начало покоя.

Капитан Шотовер (подходя к креслу). Она хочет сказать, что ее сердце не разобьется. Всю жизнь она мечтала о том, чтобы как-нибудь разбить его. А теперь она боится, что разбивать собственно нечего.

Леди Эттеруорд (бросается на колени и обнимает ноги отца). Папа, неужели ты думаешь, что у меня нет сердца?

Капитан Шотовер (поднимает ее с угрюмой нежностью). Если бы у тебя не было сердца, дитя, как могла бы ты мечтать, чтобы оно у тебя разбилось?

\section{Реперсонализация Элли:}

Элли (с просветленным лищом). Жить в благословении! Вот что мне надо. Теперь я понимаю, почему я на самом деле не могу выйти замуж за мистера Менгена. В нашем браке не могло быть благословения. Благословение в моем разбитом сердце. Благословение в вашей красоте, Гесиона. Благословение в душе вашего отца. Даже в выдумках Марка есть благословение. Но в деньгах мистера Менгена никакого благословения нет.

Как происходит деперсонализация и реперсонализация в фильме Сокурова? В целом Сокуров воспринял в большей мере идею деперсонализации. Его фильм о том, что сделал брежневский Советский Союз с людьми. 
Они погружены в свои личные дела, причем настолько, что свист пуль и пулеметные очереди проходят мимо их внимания. Сокуров и его сценарист Юрий Арабов специально ввели персонажа, которого нет в «Доме, где разбиваются сердца», - доктора Найфа (Knife нож). Этот доктор Найф - воплощение смерти и безумия. Он вырвал себе один глаз, так как, по его мнению, у человека слишком много дублирующих органов. Оно обожает анатомировать трупы и мечтает попасть на войну, чтобы там развернуть свои таланты. А пока он пытается анатомировать тело загипнотизированного Әлли Менгена (состояние под гипнозом - предельная степень деперсонализации). Это один из самых знаменитых эпизодов фильма: под музыку сонаты Доменико Скарлатти доктор Найф готовится к вскрытию, «как консервной банки», уснувшего Менгера. Вся сцена является аллюзией на известную картину Рембрандта. Менген все слышит, но не может пошевелиться. Входит Элли и со словами «Менген встань и иди» (пародия на воскресение Лазаря) будит несчастного жениха. Менген вне себя от гнева. Он начинает говорить 5-стопным ямбом Васисуалия Лоханкина:

Пока я спал, я слышал ваши речи,

Скажите мне, чудовища, почто...

Очевидно, в параллельном мире ему была уготована участь нахлебника Элли и Шатовера.

Птибурдуков, тебя презираю,

Волчица ты и мерзкая притом.

Элли у Сокурова деперсонализирована с самого начала, она показана как безжизненная кукла. Красавица Гесиона - женщина шизонарцисс (термин И. П. Смирнова). В начале фильма она сидит пред зеркалом с нарциссом в руке, совершенно бездушная и неспособная любить, что является главной чертой нарциссизма как психического расстройства.

И ненавидим мы, и любим мы случайно, Ничем не жертвуя ни злобе, ни любви, И царствует в душе какой-то холод тайный, Когда огонь кипит в крови.

Ее муж Гектор - глуповатый красавец, мужмальчик, муж-слуга, истерик, рассказывающий небылицы о том как он убил тигра, также деперсонализирован по отношению ко всем окружающим. Даже известие о самоубийстве Рендела оставляет его равнодушным, хотя Рендел совершает попытку суицида отчасти оттого, что Гектор завел интрижку с его женой Ариадной. Ариадна, сестра Гесионы, дана у Сокурова как тяжелая истеричка. Она кричит, бьется в истерических судорогах. Казалось бы, истерия и деперсонализация - несовместимы. Но вспомним книгу Эрнста Кречмера «Об истерии», где он говорит, что это наиболее животная реакция у человека и что животное (о теме животных в фильме Сокурова - ниже) замирает и притворяется мертвым при виде врага [1]. Это ли не деперсонализация? Ариадна реперсонализируется лишь в конце фильма, когда труп Рендела выбрасывают за борт «Ноева ковчега», и она плывет за своим покойным мужем. Наиболее трудна роль Менгена. С одной стороны, он хуже животного. Шотовер говорит о нем: «Душа Менгена питается свиным пойлом». Рассмотрим в этом плане фрагмент притчи о блудном сыне

У некоторого человека было два сына; и сказал младший из них отцу: отче! дай мне следующую мне часть имения. И отец разделил им имение. По прошествии немногих дней младший сын, собрав всё, пошел в дальнюю сторону и там расточил имение свое, живя распутно. Когда же он прожил всё, настал великий голод в той стране, и он начал нуждаться; и пошел, пристал к одному из жителей страны той, а тот послал его на поля свои пасти свиней; и он рад был наполнить чрево свое рожками, которые ели свиньи, но никто не давал ему. Придя же в себя, сказал: сколько наемников у отца моего избыточествуют хлебом, а я умираю от голода; встану, пойду к отцу моему и скажу ему: отче! я согрешил против неба и пред тобою и уже недостоин называться сыном твоим; прими меня в число наемников твоих (Лк.15:11-16).

С постмодернистской точки зрения можно сопоставить фрагмент «и пошел, пристал к одному из жителей страны той, а тот послал его на поля свои пасти свиней; и он рад был наполнить чрево свое рожками, которые ели свиньи, но никто не давал ему»

со словами капитана Шатовера «Душа Менгена питается свиным пойлом». Как душа может питаться свиным пойлом? Душа питается 
воздухом. Сначала приведем комментарий этого фрагмента, принадлежащий Серафиму Соровскому:

Пасти свиней: Самое унизительное для истого иудея занятие. Закон иудейский запрещал иудеям есть свинину, свинья была для них противным животным. Так нередко грешник, когда привязывается, чтобы заглушить сознание свое греховное, к какому-либо мирскому предмету, унижается еще более и доходит до самого бедственного состояния (http://www.smisl-zhizni.ru/ new-pritchi/492-o-bludnom-sine).

Как можно истолковать этот фрагмент с точки зрения эзотерического христианства? Почему блудный сын должен был питаться пищей свиней и как это связано со словами старика Шатовера «душа Менгена питается свиным пойлом». Свиньи - нечистые животные, они едят, что попало. Тот, кто поедает пищу свиней (питается, чем попало), смешивает пищу и, стало быть, смешивает доктрины, то есть прелюбодействует (в соответствии с эзотерическим христианством Мориса Николла). Как же прелюбодействовал Менген? Он смешивал капиталы разных людей, получал прибыли, сразу вкладывал их в другой бизнес, манипулируя людьми и деньгами. Но причем здесь прелюбодеяние? Менген хотел жениться на молоденькой девушке Элли Дэн, с которой он хотел совершить прелюбодеяние в широком смысле. Таким может быть толкование этого фрагмента притчи о блудном сыне.

Но, с другой стороны, именно как животное Менген разительно отличается от всех остальных персонажей, человекообразных кукол. На «Валтасаровом пиру» (к нему зажарили кабана Балтасара) он два раза отвратительно поперхнулся. «Валтасаровы пиры» (экранизация романа Фазиля Искандера «Сандро из Чгема» - еще одна ассоциация со Сталиным). Шотовер устраивает «Валтасаров пир» накануне конца света, а в фильме «Валтасаровы пиры» пир устраивает Сталин. Сам Шотовер в фильме Сокурова (да и в пьесе Шоу) - единственный недеперсонализированный персонаж. Он остается живым от начала до конца действия. Возможно, это связано с многогранностью его ассоциативных идентификаций - Сталин, пророк Моисей (так его называет в начале фильма Менген), Шекспир (как двойник Шоу, который иронически называл себя Шекспиром XX века), Христос, при- зывающий всех к покаянию,ветхозаветный Бог, спасающий людей на Ноевом ковчеге, Ной, поскольку он и сам находится в этом ковчеге, наконец капитан Ахав из «Моби Дика»:

- А как насчет гарпунной пушки?

- Никакого толку. Это на китов, а не на людей.

В финале фильма на Ноевом ковчеге все реперсонализируются, на лицах у всех живое и страдальческое выражение. В отличие от пьесы Шоу персонажи Сокурова страстно хотят выжить.

Большую роль в фильме Сокурова играет архетип дома. Что такое дом? В соответствии с теорией травмы рождения Отто Ранка дом это прежде всего материнская утроба, в которую каждый человек вновь хочет попасть, чтобы спрятаться в ней от неуютного и страшного мира [7]. Но дом Шоу-Сокурова - особенный. В нем разбиваются сердца. Само это сочетание broken harts - странное: сердце как нечто неживое, что можно разбить, сердце как елочная игрушка, сердце как странный объект (в смысле У. Биона). С другой стороны, дом капитана Шотовера это корабль, на котором плывут деперсонализированные люди, живые мертвецы - «Летучий голландец». Наконец словосочетание «дом скорби», давшее первое слово названию фильма Сокурова, дает значение «сумасшедший дом». Это бесплодный дом, матка, которая нечего не рожает. Тем более, что мать Гесионы и Ариадны была африканской ведьмой, на которой женился Шотовер на Занзибаре, где он продал душу дьяволу. В этом сумасшедшем доме и сумасшедшем мире умирает старик Шоу. В фильме показаны документальные или квазидокументальные кадры, где умирающий Шоу говорит, что когда он умирал (то есть он говорит с того света, $к$ тому же голосом Сокурова) радио предложило ему поставить какую-то мелодию; они думали, что он выберет какую-то классическую мелодию. Но он выбрал песню «Умирает старая корова».Тема животных, которую мы слегка затронули выше, далеко не случайна. Старик Шоу за кадром говорит в том духе, что люди страшнее животных, что лев никогда не станет убивать то, что он не собирается есть. Эта фраза сейчас кажется банальной, но вспомним, что фильм Сокурова был сделан еще в Империи Зла, поэтому противопоставление животных людям-чудовищам была весьма актуальна. В соответствии с этими фильм Coкурова буквально наводнен животными. По- 
пугайчики, кабан Балтазар, тигр, на которого якобы охотился Марк-Гектор, болотная птица, колибри (груди Ариадны, как их называет тот же Гектор), собака («Собака ты моя!» - говорит Гектор Ариадне, что является едва ли не единственной отсылкой к Чехову, который в письмах называл собакой свою жену Ольгу Книппер), умирающий белый медведь в документальных кадрах, бегущие жирафы - последний кадр фильма. Наконец три поросенка из диснеевского «Ho's afraid this big bad wolf”, где волк, конечно, Менген, а поросята соответственно Гесиона (Наф-Наф), Ариадна (Нуф-Нуф) и Элли (Ниф-Ниф), которая превращается в волчицу.

Бернард Шоу, обесцененный советским литературоведением, недооценен западной философией.

Мне кажется, что в истории про Генри Хиггинса и Элизу Дулитл, написанной незадолго до первой мировой войны и служащей своеобразным прологом ко всему тому, что будет сказано ниже, было впервые заявлено на весь мир, что реальность опосредована человеческим языком, а мир вокруг человека таков, каким его язык выражает. И что, в сущности, человек есть то, что и как он говорит. Если бы вы знали, - признается Хиггинс собственной матери, - как это интересно, взять человека и, научив его говорить иначе, чем он говорил до сих пор, сделать из него совершенно другое, новое существо. Да, мы знаем, что это действительно очень интересно. Кажется, все столетие только этим и занимались. В пьесе Шоу мне кажется наиболее примечательным тот оптимизм, с которым европейская культура в лице профессора Хиггинса вступает в новую, лингвистически-философскую стадию своего развития: перегородки между людьми и классами языковые: надо найти общий язык - и тогда они исчезнут. Но вот прошло полвека, и оказалось, что языка - слишком много, что им фактически все и исчерпывается, и, отказавшись от языка, человек просто погибает.

Представим, что вы едете в поезде. Что происходит с вами? Кажется, ничего особенного. Вы слышите стук колес, но думаете о чем-то другом, читаете какую-то книгу, в соседнем купе плачет ребенок, в окне проезжают мимо деревья, вы слышите разговор соседей по купе, но не понимаете, о чем идет речь, потому что они разговаривают, кажется, по-эстонски. Вас раздражает, что по радио передают какую-то идиотскую передачу. У вас болит голова, в купе душно, ваше лицо в зеркале напротив вам решительно не нравится. Вот маленькая модель семиотической реальности. Очень много информационных сигналов совершенно различной природы, часть из которых вам совершенно не нужна, а часть просто мешает. Но вот все меняется. Ребенок перестает плакать, соседи переходят на русский язык и предлагают вам чаю, по радио слышна хорошая музыка, поезд останавливается в каком-то неизвестном городе. Вы перестаете читать, начинаете разговаривать с соседями, голова проходит, вам хочется умыться. Соседи спрашивают, куда вы едете, и конечно от того, куда вы едете, откуда и зачем, все, что находится вокруг, будет приобретать или утрачивать значение. Конечно, это только пример. Здесь не содержится никакого метода изучения реальности как знаковой системы. Возможно, что такого метода никогда не удастся разработать, возможно, что он и не нужен, как не нужна карта, полностью совпадающая с реальностью. Но эта карта, если говорить о реальности, и невозможна. Попытка картографировать хотя бы один момент во всей реальности, как мы это сделали в примере с поездом, обречена на провал. Нельзя одновременно и равнодоступно охватить и описать все точки внутреннего и внешнего пространства пусть даже одной нашей планеты. И поэтому нельзя сказать, что сейчас, в данную минуту, что-то точно существует, а чегото нет. Потому что люди поминутно рождаются и умирают, а те, кто живы и дееспособны, все время вольно или невольно вводят друг друга в заблуждение. Если в данную минуту мое сознание располагает некой суммой информации о мире, содержащейся в виде пропозициональных установок, то только это говорит об определенной стабильности мира во мне и вокруг меня. Это те самые границы моего мира, которые совпадают с границами моего сознания, и о которых писал Витгенштейн [6].

\section{Библиография:}

1. Кречмер Э. Об истерии. Спб: ПИТЕР, 2001.

2. Меграбян А. А. Деперсонализация. Ереван: Менцриба, 1962. 
3. Николл М. Цель. М.: СТАРЛАЙТ, 2009.

4. Руднев В. Философия языка и семиотика безумия. М.: Территория будущего, 2007.

5. Руднев В. Новая модель сновидения. М.: Академический проект, 2014.

6. Руднев В. Морфология реальности // http://www.libok.net/writer/1777/kniga/5252/rudnev_vadim/ morfologiya realnosti/read/

7. Руднев В., Чистяков А. Территория ДОК: Философия загородного домостроения. М.: Domus DOK, 2013.

\section{References (transliterated):}

1. Krechmer E. Ob isterii. Spb: PITER, 2001.

2. Megrabyan A. A. Depersonalizatsiya. Erevan: Mentsriba, 1962.

3. Nikoll M. Tsel'. M.: STARLAIT, 2009.

4. Rudnev V. Filosofiya yazyka i semiotika bezumiya. M.: Territoriya budushchego, 2007.

5. Rudnev V. Novaya model' snovideniya. M.: Akademicheskii proekt, 2014.

6. Rudnev V. Morfologiya real'nosti // http://www.libok.net/writer/1777/kniga/5252/rudnev_vadim/morfologiya_ realnosti/read/

7. Rudnev V., Chistyakov A. Territoriya DOK: Filosofiya zagorodnogo domostroeniya. M.: Domus DOK, 2013. 